\title{
We praise our heroes: Notes, translation of "The School of Vienna at Prague" by Jean Cavailles. - and the limits of our world.
}

\author{
Camille Akmut
}

\begin{abstract}
In this highly influential 1935 text, Jean Cavailles, after describing the historical sociological characteristics of the so-called "Vienna Circle", turns to an analysis of Wittgenstein's Tractatus Logico-Philosophicus, and three of its thesis specifically which he considers to be central to the understanding of their ideas. Vienna Circle : a diverse group of philosophers and scientists, and philosopher-scientists, and scientists-turned-philosophers, from the whole array of disciplines, mathematics to social sciences, that met regularly at the University of Vienna in the 1920s and 1930s until the rise of far-right politics forced them into exile, or killed them. Before Nazism, they organized meetings and talks to make sense of important advances and works of the sciences of their times; discussions out of which emerged theirs, which Cavailles renders here for us.
\end{abstract}




\section{Jean Cavailles (1903-1944) : and ( $\vee$ ) the end of abstract philosophy and science. (The Duties of Genius.)}

Before joining the Resistance and becoming the "philosopher-mathematician loaded with explosives, a tenacious realist, resolute without optimism", as described and immortalized by Georges Canguilhem, and later in Melville's Army of Shadows (1969), Cavailles had made multiple stays in Germany in the early 1930s where he had either learned German or perfected his pre-existing knowledge of it (a knowledge seen throughout the text, where he makes regular references to the original publication of the Tractatus Logico-Philosophicus, in German, in 1921).

It was during these early years that he had met German mathematician Emmy Noether in Göttingen (almost universally held to be the greatest female mathematician in the history of that discipline) with whom he later worked on common projects.

Jean Cavailles was 31 years old when "The School of Vienna at the Congress of Prague" was published. In January of 1935, in a major journal of his days. Soon afterwards he was appointed as what may be described as the modern-day Assistant Professor, at the University of Strasbourg.

Following the publication of this article on the Congress at Prague, he went on to publish an edition with Noether of the correspondence between Cantor and Dedekind (both German mathematicians, both made important contributions to set theory) in 1937 (Briefwechsel...).

1939. The Second World War meant that certain questions, previously only discussed abstractly by our philosophers, would take on the urgency and practicality of life and death matters, and ceased, and could never be again, and would never be again abstract only. The old large questions : what is a good life, why is there something rather than nothing, all of it, would soon receive their answers for everyone. But, not the same.

In the case of one professor in Freiburg, who had never been, or felt better perhaps, whose cheeks had never been rosier, never perhaps written as much, including many letters about his Jewish colleagues, all the while theorizing about the intricacies of the relationships between Sein and Dasein, while his life itself had been so bottomlessly pitiful : in the case of the queer Martin Heidegger it meant that education and knowledge could be separated from action. - a lesson on education that we know too many of our professors to share.. and, we'd rather not know what if, if (the same as now probably, the safest of all possible worlds).

Meanwhile, what can only be rightfully called a hero, ours :

In the case of Jean Cavailles, who had received the best of educations, such tortures of the mind had never occurred.

He didn't talk. He didn't try to avoid his responsibilities, he, who, due to his stature, would have had many ways to avoid them we are sure. We praise our heroes : We remember them, protect their memory; and keep them, though in that sense only unfortunately, alive. A life cut half.

Preferring direct action over the relative comfort and security of a 
previous assignment within the French Resistance, he would not live for much longer... Betrayed, imprisoned along with his sister, tortured by the Gestapo, killed, body thrown away like trash in an anonymous grave numbered 5 - before reaching the age of 40 , at 39 .

So, died one of the great intellectuals of the past century - a heart of gold without which intellect is consistently, always sterile. - a lesson they have not learned, and perhaps cannot learn. "The limits of our world..."

This all occured for the same reasons that soon would make it impossible to talk about philosophy at the University of Vienna, and much of the rest of Europe.

In "The School of Vienna at the Congress of Prague", Jean Cavailles describes also, though unintentionally, the last hours before these many events. A time when Schlick was still alive, a time when philosophy could still be debated and talked about in abstract terms, and he was still alive.

A world that would soon cease to exist.

They had robed an entire generation of Cavailles, a good heart paired with a good mind, but had against their wishes detonated one last bomb of his, a self-defense mechanism or trap of sorts : celebrated as a hero after the War ended - a celebration that does not stop - and while he had disappeared, his legacy had not, it became a part of everyone, and was everywhere.

Not least thanks to the efforts of Georges Canguilhem, who during the war had also fulfilled his own duty, as a doctor of medicine, in the Resistance, and wrote a book-length celebration, Vie et mort de Jean Cavailles (Life and Death of Jean Cavailles, not translated in English, and many of their writings), for the friend he had lost, a friend lost, but not forgotten.

He bore witness. (Like James Baldwin had done for Malcolm X, Martin Luther King, Medgar Evers, all of his friends, who were now also dead.) The importance of this cannot be overstated. While history tends to lend itself to a view of it as a necessity (contingency writes Cavailles), after the facts, there could have been many worlds, possible worlds, actualized among all possible ones, where Cavailles would have been doubly robbed from us, killed and forgotten. But, thankfully for all of us, such had not been the case, and no such things happened.

In introducing this text, we made the bold claim "a highly influential text". Let us explain what we mean exactly now : influences on later generations of philosophers, from Pierre Bourdieu to Michel Foucault, philosophers-turned-sociologists, philosophers-turned-historians-though-notaccepted-as-such, can be seen everywhere, and we mean everywhere, in this text.

The reader will take good note when Cavailles writes of "fields" and "spaces" ("The field of relationships between these objects is the logical space...") and later of "common language", and when he also variously writes of "discourse", "architecture" (and more "architectures of truths"), "representation" and "we cannot think illogically".

His developments on language, time, the limits of our world, logic and history, altogether, all together, were influential; exploded, everywhere.

But, read more, pay attention, and discover more : "As its last refuge - logic - is altogether [radically] sterile, philosophy cannot pretend to the 
status of doctrine" (it will only be a critic of language from now on). A guide, a father, intellectual, to all - all who mattered, and listened. And, listen they did. Those who mattered, our (new) new heroes.

We have not yet begun to understand the major role played by Jean Cavailles on so many.

In other ways, this text also most likely contributed to the broad dissemination of Wittgenstein's ideas in France in the 1930s, and in that way, Cavailles, who possessed rare characteristics amongst his peers (the combination of an old, humanistic education paired with a knowledge of science, mathematics in his case specifically, a combination we know to be explosive), and possessed the right mind to identify the right minds, played the role of a pioneer. And, a guide, for all of us, the old and new generations that came after him, and through him, and through them.

But, let's turn to its language, as this text is all about language :

"We can fix", "other worlds", "different ways", "to respect", "comfort(s)", "starting points", "one architecture can be replaced by another", "(the) last refuge", "incertitudes", "to fight" ("lutte")...

What a beautiful text. What a beautiful man. A beautiful mind, most. But, most important : a golden heart. (The duties of genius...)

But, one must read between the lines - the interstices of language and history, those that preoccupied the next generation so much. We hope to have done them justice, all of them, here.

This makes it perhaps Cavailles' most important text. Not forgotten!

What we did, precisely : "muddling", and "meddling", and fighting with, and alongside it, and its language, and languages (those of mathematics and set theory), and the equations we did not know before starting, the letters : heartbroken, and heart warmed simultaneously.

We praise those who showed so much courage. In their intellectual lives, in their lives. Detonating bombs on bridges, and in our hearts. Vibrations of which continue to resound ...... . 
For the ease of the reader, and others :

The text is structured in 3 parts : 1 . Brief remarks on the historical sociological characteristics of the Vienna Circle as it presented at the Congress of Prague 2. Three theses from Tractatus are analyzed by Cavailles and 3. (beginning with page 141 in the original text) The ideas of the Vienna Circle proper, and their divergences from, and novelties compared with, and breaches with 2 ..

Where we have made errors in rendering the ideas or language of Cavailles, we apologize, but better than nothing, and better than this world, and others may, will build on what we have done. That is all OK. (Hacker ethic above everything. Better than nothing, better than not to start.)

To further clarify our intentions : this most important text is given here in an original English translation, accompanied with notes by the translator and an introduction, in the public interest, not just (that of) researchers, computer scientists or mathematicians, social-scientists-turnedit, or whomever else, but in the interest of the wide public and the many varied communities in our society (hackers, freaks, phone phreaks, golden hearts, self-taughts, school drop-outs, squatters, free sofware developers, writers of songs like "Hattie Caroll" or "Cop Killer", the old and new one, all of it all, we love you all).

Oh, must our professors resent being associated with them, or to have to even read about them, we can almost hear their teeth grind, and see their faces distort : people they have long ago abstracted themselves from, not found in any of their books, papers that can only be bought. But, Cavailles was from the people. Our boy. Dad, military.

That's not something that they're going to take from us. Our own.

He too had "muddled" with the "material" of his days. In their bottomless quest for abstraction, they will not be able to abstract this away.

Finally, and, on the other hand : No matter what interests others may have, may claim to be theirs, may claim to be that of the courts, earthly or otherwise divine, military or sham, this text just cannot be taken down.

In producing this translation, we have created many problems, and solved many other ones. (But, you do better.) 
JEAN CAVAILLES

THE SCHOOL OF VIENNA

AT THE CONGRESS OF PRAGUE

One of the great events of this congress was the first appearance of the "Vienna Circle" in front of such a large philosophical gathering - as a constituted group. At Oxford, M. Schlick ${ }^{1}$ had been about the only one to represent similar ideas to that of the "Circle". At Prague, city of Bolzano and Ernst Mach, the new school, in full, was able to assert the unity of its views, and establish the significance of the results they had already acquired vigorously. The sessions of one of the sections had almost entirely been dedicated to them : the study of their doctrine, the discussion of the problems raised by other philosophies, and, finally, the development of some applications. The ideas of Wittgenstein ${ }^{2}$, we know, had played a major role in its constitution, and contributed, at least in part, to its novelty when compared to that of Mach, of which it otherwise understood itself to be a continuation. Three theses of the Tractatus played a major role in this regard. First, language is a reflection of our world, this is to say : the whole of reality is a given, independent from knowledge of which it is merely a description; on the other hand, the latter is a particular case of the general fact that is our ability to represent the universe based on one of its parts. The notion of an establishment of a correspondence plays a central role here : it is defined by the preservation of a system of essential relationships related to its structure, of the model as well as its image. The specifics of the preserved relationships has an effect on the order of the representation : spatial, for instance, if certain geometrical relationships remain. But, there exists one invariant necessary to any image-model pair : the logical articulations of reality. "Any image is also a logical image." ${ }^{3}$. These relations, that are the most general, are evidenced by the gap between possible and real. The world is a system of actually-existing situations (Was der Fall ist ${ }^{4}$ ), actualized

\footnotetext{
${ }^{1}$ Trans. note. Moritz Schlick (1882-1936), birth in Berlin, death in Vienna, physicist under Max Planck-turned philosopher, member of the Circle, assassinated by a former student as he was ascending the stairs of the University of Vienna, the events of which served to bolster the far-right of the time.

${ }^{2}$ Trans. note. The following discussion of the Tractatus Logico-Philosophicus corresponds to the best of our knowledge to about a graduate level discussion of this book. It overlaps in many places with that we remember having received at the University of Heidelberg. The faults of philosophical discussions of Wittgenstein (not present here) : all of the underlying mathematics abstracted away as if they did not matter, even though such was never the case and had never been the case for the author, here Wittgenstein.

${ }^{3}$ Tractatus, proposition 2.182 .

${ }^{4}$ Trans. note. Literally, "What the case is", and perhaps more clearly, "What is the case".
} 
amongst all other possible situations in a contingent manner : the permanent element, or substance, of the world are the objects (Gegenständen ${ }^{5}$ ) involved in these situations and - though having no more autonomous existence than words outside sentences - holding in themselves the entire world of possibilities ${ }^{6}$ of participation with these possible situations. The field of relationships between these objects is the logical space, in the same way as the geometrical space is the domain of varying relationships within that space. As such, logic does not presuppose the actually-existing world, but merely, or more generally that there is a world (5.552). - "The logical image of the world is thought." (3). But, as thought is in turn projected into language, "the proposition is thought as being able to be perceived by the senses" (3.1), we find here thus an application ${ }^{7}$ of the real universe on the universe of discourse [language]; "to objects (Gegenständen) correspond the names, to actually-existing relationships the content of propositions (3.22) : "the proposition is a model of reality" (4.01). Out of this two consequences emerge : on one hand, networks of limits ${ }^{8}$ between our world and our language : if, "the limits of our language are the limits of our world" 9 (5.6), inversely "the boundaries of logic are also the limits of our world" (5.61). It is equally absurd to picture a world that would exist outside of logic as it is to try to discourse [speak] on something other than the world ${ }^{10}$, be it its boundaries. ${ }^{11}$ On the other hand, one ought to distinguish for every proposition between meaning and truth value : meaning embeds it in the space of logical possibles, while truth or falseness ${ }^{12}$ - links it to the system of actually-realized configurations. In a symbolic language ${ }^{13}$ - common languages ${ }^{14}$ are to be avoided both on account of the ambiguity of their terms and the complexity of their syntax (4.002), ${ }^{15}$ - one only meets more-or-less complicated architectures [but they are correct : "we cannot think illogically [outside of logic]"]

\footnotetext{
${ }^{5}$ Trans. note. Just, objects.

6 Trans. note. "virtualité" says the original French text succinctly.

7 Trans. note. Cavailles qualifies this application as "bi-unambiguous" ("bi-univoque" in the original).

${ }^{8}$ Trans. note. Cavailles here uses the fairly, up to highly unusual, and now antiquitated "bornes" (bounds or boundaries) instead of the (now) more commonly used "limites" (limits). ${ }^{9}$ Trans. note. A most famous (and true) quote.

${ }^{10}$ Trans. note. A lesson our professors, who read this text, as they so often do, as a matter of pure abstraction, ought to keep in mind.

${ }^{11}$ Trans. note. Language is everywhere, we cannot escape it. In the end, no matter what field we choose to engage in, it all comes down to language, as one soon discovers - no matter if computer science, mathematics, economics or whatever else...

${ }^{12}$ Trans. note. Not to be confused with falsehood : falseness is the (logical) state of being false, or non-true. (As all of these things are commonly understood within set theory.)

${ }^{13}$ Trans. note. E.g. the language of set theory. (Or, now (modern) programming languages, and before them lambda calculus, the one of Alonzo Church, about contemporary with this text.)

${ }^{14}$ Trans. note. Which we would now describe, as it is done in computer science, as natural languages (and before this, we believe, in linguistics, based on the work of Noam Chomsky, and the Chomsky hierarchy). (To distinguish them from programming languages.)

${ }^{15}$ Trans. note. Set theory, as well as programming languages, represent a much more succinct way of expressing relationships between various objects (which are also called objects there, at least in the dominating paradigm of "objected-oriented programming" (as opposed to functional programming, where functions are central instead).
} 
of propositions to be verified empirically. There are no other sources of truth.

It is, in fact, the second thesis of the Tractatus - necessarily linked to the first anyhow - that purely logical propositions have no content, they are tautologies. "All of propositions of logic say the same things, which is to say nothing." (5.43) ${ }^{16}$ Indeed, it suffices to turn to Frege and Russel, to understand or deepen this. Contrary to what they thought, there are no logical [logic] constants. The equivalence itself of different combinations shows already that they have no independent existence (ex $: \sim p \vee q$ equivalent to $p \supset q)^{17}$. But, the notion of function of $\operatorname{truth}^{18}$ dominates all of logical calculus [le calcul logical $]^{19}$. Given a certain number $n$ of elementary propositions as starting points, there are $2^{n}$ possible distributions of the values $\mathrm{T}$ and $\mathrm{F}$ between themselves ${ }^{2021}$. If we were to take (let us take) a proposition dependent on these $n$ propositions, we can fix [establish] the relationship between its truth and those of these $n$ propositions in $2^{2^{n}}$ different ways. For two base propositions $p$ and $q$ there are thus 16 truth functions [functions of truth] : for example, the function $p \supset q^{22}$ corresponds to / is an abbreviated notation for the following correspondence $[\text { truth table }]^{23}$ :

\footnotetext{
${ }^{16}$ Trans. note. When Wittgenstein was done defending his $\mathrm{PhD}$ thesis, in Cambridge, he stood up, walked to Russel, a distinguished man if any, we know, no feeble mind we know, though all the wrong political opinions, tapped him on the shoulder and proclaimed (Wittgenstein who had a hard time dealing with academics, for reasons of his own) : "You'll never understand." (This, we believe, is something that can be found in the reference biography by Monk, where everything else can be found as well.)

${ }^{17}$ Trans. note. This is where things start to get tricky, if they had not already been before. But, bear with us. (The mathematicians and computer scientists will move on with their reading.) Cavailles here stresses the fact that different propositions of logic, or logical propositions, can have (about, $\sim$ ) equivalent meanings. A fact, he sees as meaning they have no independent existence. We do our best here to render the meanings of these mathematical developments : $p \vee q$ means simply p OR $\mathrm{v}$, in the (succinct, symbolic) language of set theory. This is to say : if one is true, or both are, then the outcome of both is true as well (ex : 1==1 || $2==3$ evaluates to True in the programming language Haskell). This is also a simple axiom or part of set theory. But, if this is true, and it is, then that proposition is (about $\sim$ ) equivalent to the other : $p \supset q$, the proposition $p$ implies the proposition $q$.

${ }^{18}$ Trans. note. That is literally what set theory is : a collection, or library, of functions (most of which of the kind), with inputs (ex : the propositions $p$ or $q$ e.g. $1>0$ and $1000=1$ ) and outputs, of truth, and non-truth, etc.

${ }^{19}$ Trans. note. In other words, the calculus, and operations, just described.

${ }^{20}$ Trans. note. "T" and "F" stand respectively for true and false, as is commonly understood to be the case (with)in set theory (language, application

${ }^{21}$ Trans. note. The original keeps with "V" throughout (V for "verite", or truth/true). In the case of false, there are no such misunderstandings or ambiguities, as both languages overlap, the French and English both say : false, faux...

${ }^{22}$ Trans. note. This is what we were talking about earlier on (in the previous note, just above).

${ }^{23}$ Trans. note. Cavailles keeps talking about correspondence ["correspondance"], who knew what it was, and meant. But, this terminology is then readily reused by our philosophers, and most of all epigones of said philosophers, without any clue of what it means; but this is what anyone would call a truth table. You can search for it. (It's really common stuff.) (And, explicitly, nothing to be in awe of if you come from the humanities or social sciences. Just open up a textbook, any, really : e.g. ones on "Logic" (philosophy) or "Discrete Mathematics" (computer science) (like the one by Susanna Epp, "with applications"), sometimes also "Mathematical Foundations (of Computer Science)", and mathematics we don't know
} 
Any architecture of overlapped truth functions ${ }^{24}$ will not have for any other principle than to respect the definitions of intermediary functions and the rules of the calculus of combinations ${ }^{25}$. The fundamental symbols and the rules of their usage is thus arbitrarily chosen following rules of comforts [convenience] : for Wittgenstein, the easiest is the [connex or linked, iterated $\left.{ }^{26}\right]$ negation $p / q$ (non- $p$ and non- $q$ ). The general expression of a proposition will thus be written like so $[\bar{p}, \bar{\xi}, N(\bar{\xi})]^{2728}, \bar{p}$ meaning the system of propositions that we start from [we use or take as starting points], $\bar{\xi}$ the general term obtained through iteration, $N(\bar{\xi})$ the term following $\bar{\xi}$ ([connex or linked] negation of all $\xi$ ). In the system of truth functions [functions of truth] that can be defined for $n$ given propositions, we distinguish at the two extremities, the tautology and the negation/contradiction ["contradiction"] which take on, the one the value $\mathrm{T}$, the other the value $\mathrm{F}$, whatever values we may attribute to variables. The tautology is useful as it enables simplifications through substitution of one architecture ${ }^{29}$ by another, exactly like the equation, of which it is a particular in some other way (Example : $p \supset q . p: \supset: q$ ). It is a method of zero of sorts (6.121). Independently from its technical (clarification) merits [advantages] (so, for instance, in the case of type theory and the elimination of the axiom of reducibility thanks to the distinction between function and operation), this theory thus enables us to assign its role with regards to philosophy, precisely. As its last refuge - logic - is altogether [radically] sterile, philosophy cannot pretend to the status of doctrine (4.112), it will merely be "critic of language" [language critic] (4.112). Its only goal (from now on), "the clarification of propositions" (4.112). It will limit [bound] itself to fight [the fight] of the constant insurrections occurring in our language, pseudo-problems caused [provoked] by the syntactical incertitudes [uncertainties] of common language : "the

and don't care to look up, but you do.)

${ }^{24}$ Trans. note. Again, if you are a philosopher-no-mathematician, stop reading this with your lenses : "overlapped truth functions" is literally what Cavailles has done in the previous figure. (There are no mysteries here, and there's nothing to philosophize about. (Muddle!))

${ }^{25}$ Trans. note. Elsewhere, also, and already : calculus of logic, logical calculus, etc. e.g. set theory, its functions, and "calculus" (i.e. the operations performed, on these various objects, with these various functions).

${ }^{26}$ Trans. note. "connexe iteree". Here, we, too, have reached the limits of our world, and language: we do not know what Cavailles refers to, but he says what he means in parenthesis. (By "connexe" he seems to be describing bar, this we take from the following passages.)

${ }^{27}$ Trans. note. Lowercase Greek letter xi. (e.g. Riemann Xi function.)

${ }^{28}$ Trans. note. e.g. $\bar{x}$ is a bar, also referred to as overbar (or overline). "A set stripped of any structure besides order" (Wolfram).

${ }^{29}$ Trans. note. The same architectures (of truth functions!), that he was talking about earlier on, of which he has given one example in the figure. 
majority of questions and propositions of [our] philosophers rests on that we do not understand the logic of our language." (4.003).

$(\ldots)$

Such was the starting point of the "School of Vienna" (...) 


\section{Bibliography by the translator}

Cavailles, Jean. 1935. "L'Ecole de Vienne au congres de Prague" Revue de Metaphysique et de Morale 42(1) : 137-149. ["The School of Vienna at the Congress of Prague"]

Description : the original (our boy!).

Wittgenstein, Ludwig. [1921]. Tractatus Logico-Philosophicus.

Description : pick the German one, that we think Cavailles used, or/and the English edition, or whatever you can, or whatever you like (but start we/you (all) must).

Monk, Ray. Ludwig Wittgenstein: The Duty of Genius.

Description : Reference biography. Wittgenstein came from exceptional backgrounds, he literally grew up in a museum. Backgrounds that made him hard to live with, and for him hard to live with others, he had a "heavy dislike" for academics, threatening them with "objects" when he had to suffer and sit through their idiotic thoughts and talks, finally saying goobye-fuck-you to all for 20 years? (I read the hardcover edition, in two volumes I'm pretty sure, bought in a second-hand shop up the hill.)

Epp, Susanna. Discrete Mathematics with Applications.

Description : this is as good as any (start!). 


\section{Acknowledgements}

Dedicated to P.-Y. : you, who made me feel normal at a time when no one else did. And, I think that I loved you. Discussions with you while you were cooking, fried sausages and steamed vegetables while I only ate pasta, Berthold Brecht quotes ("Erst kommt das Fressen dann die Moral"), Murnau and Rainer Werner Fassbinder and Alexanderplatz, are the best and only things I remember. The black-and-white tiling hall, where I think I saw you last : and, where a many times I saw a noble lady wearing various designer dresses, she liked frill, one for every day of the week, she certainly did not come "from the people". And all the things I've forgotten, because not all of them were that great. (A gold prison is still a gold prison. (My first hack, one that required much courage!))

Pierre Bourdieu : my intellectual father, in all ways, always, nowhere because everywhere, who taught me everything, including where to go, including in some abstract way how to do it, including the most important (to be oneself, simply, a task so hard) : a guide like Cavailles, and Canguilhem, and Marx, and all the others, had been to him, but a very special one to me, and to so many others, I know, and all the things they too couldn't think or do, "the limits of our world". We are of our times, and cannot escape them. We choose heroes that resemble us, but different.

To you : In releasing this text, we are very hopeful! We cannot wait to see what you and others will do and come up with, and hope that they will not err, and be able to go further than we were (all) able, with what we were able to do... Godspeed to you! 